\title{
Prevalence and antimicrobial susceptibility profile of listeria species from ready-to-eat foods of animal origin in Gondar Town, Ethiopia
}

Legesse Garedew ${ }^{1 *}$, Ayele Taddese ${ }^{2}$, Tigist Biru ${ }^{3}$, Seleshe Nigatu ${ }^{3}$, Elias Kebede ${ }^{3}$, Mebrat Ejo ${ }^{3}$, Abraham Fikru $^{4}$ and Tamiru Birhanu ${ }^{5}$

\begin{abstract}
Background: Listeriosis, mostly caused by Listeria monocytogenes species, has become a major concern to public health authorities due to its clinical severity and high mortality rate, particularly in high risk groups. Currently, there is limited information regarding the prevalence and antimicrobial susceptibility profiles of listeria species in ready-to-eat foods of animal origin in Gondar town, Ethiopia. The aim of this study was to determine the prevalence and antimicrobial susceptibility pattern of Listeria species isolated from ready-to-eat food of animal origin from public dinning places in Gondar town, Ethiopia. A cross sectional study on ready-toeat foods of animal origin sampled from major supermarkets, butcher shops, pastry shops, restaurants and hotels was carried out. Culture, biochemical and sugar tests were conducted for listeria species identification and disc diffusion test was performed to study the antimicrobial susceptibility profiles of the isolates.

Results: Out of 384 food samples examined, 96 (25\%) were positive for Listeria species. Listeria monocytogenes was detected in 24 (6.25\%) of the samples. Listeria monocytogenes was isolated from cake, raw meat, ice cream, minced beef, fish, unpasteurized milk and pizza in that order from higher to lower rate. Assessment of antimicrobial susceptibility profile of $L$. monocytogenes revealed the presence of four multi-drug resistant isolates. The higher resistance rate was recorded for penicillin, nalidixic acid, tetracycline and chloramphenicol, in decreasing order. All $L$. monocytogenes identified in the current study were sensitive to amoxicillin, cephalothin, cloxacillin, sulfamethoxazole, gentamicin and vancomycin.

Conclusions: The presence of $L$. monocytogenes including drug resistant and multidrug resistant isolates in some ready-to-eat food items is an indicator of the presence of public health hazards to the consumer, particularly to the high-risk groups. Hence awareness creation on food safety and implementation of regulations about the use of drugs in humans and animals is strongly recommended.
\end{abstract}

Keyword: Listeria, prevalence, foods, antimicrobials, susceptibility, Gondar

\section{Background}

Listeriosis is one of the important emerging zoonotic diseases affecting human health following consumption of contaminated foods of animal origin [1]. Twenty to thirty percent of clinical infections of listeriosis result in death. Among the different species of the genus Listeria, L. monocytogenes is the causative agent of listeriosis [2].

\footnotetext{
* Correspondence: legesse_Ig@yahoo.com

'St. Paul's Hospital Millennium Medical College, Department of Microbiology, Addis Ababa, Ethiopia

Full list of author information is available at the end of the article
}

Listeria species are ubiquitous in the environment and possess unique physiological characteristics that allow growth at refrigeration temperature [3]. High-risk food items associated with listeriosis are ready-to-eat foods including refrigerated but do not undergo any substantial heat treatment before consumption. Major changes in food production, processing and distribution, increased use of refrigeration as a primary preservation method, changes in the eating habits particularly towards ready-toeat foods, and an increase in the number of people considered to be at high risk for the disease are suggested as 
possible reasons for the emergence of human food-borne listeriosis [4].

Previously susceptible $L$. monocytogenes become resistant to antimicrobial drugs currently in use for both human and veterinary medicine [5]. Currently, there is inadequate information regarding the prevalence and antimicrobial susceptibility patterns of Listeria spp. in foods in Ethiopia especially in Gondar. Therefore, the present study was undertaken to determine the prevalence and antimicrobial resistance profiles of Listeria species isolated from ready-to-eat foods of animal origin samples collected from Gondar town, Ethiopia.

\section{Methods}

\section{Study area and study period}

The study was conducted from November 2012 to June 2013 at Gondar town public dinning places. Gondar is located northwest of Ethiopia at latitude and longitude of $12^{\circ} 36^{\prime} \mathrm{N}$ and $37^{\circ} 28^{\prime} \mathrm{E}$. Its altitude is 2200 meters above sea level. The maximum and minimum temperatures of the area are $30.7^{\circ} \mathrm{C}$ and $12.3^{\circ} \mathrm{C}$, respectively. The total human population of the town is estimated to be 206,987. Gondar town, as one of most visited historical place in Ethiopia, hosts large number of visitors including foreign tourists [6]. According to the information obtained from Gondar town trade and industry office in 2013, there are about 273 licensed public dinning establishments including 80 hotels, 18 restaurants, 65 bar and restaurants, 20 pastry and 90 butchery shops.

\section{Study design and sampling}

A cross-sectional study was conducted to determine the prevalence and antimicrobial susceptibility profile of Listeria isolates from foods of animal-origin samples purchased from a randomly selected public dinning houses (cafeterias, hotels, restaurants, pastry and retail shops) in Gondar town. Study samples were collected using simple random sampling based on proportional allocation from a complete list of public dinning places of the town.

Since there was no previous study in the area, sample size was estimated by taking $50 \%$ expected prevalence with 95\% confidence interval and 5\% desired accuracy level [7]. Accordingly a total of 384 food samples consisting of 50 raw and 50 pasteurized milk, 40 cheese, 65 cream cakes, 20 ice cream, 85 minced raw meat, 24 pizza and 50 fish foods were collected aseptically using sterile plastic bags and transported immediately using icebox to microbiology laboratory. Out of each sampling unit that consisted of $100 \mathrm{~g}, 25 \mathrm{~g}$ analytical units were subsequently removed for microbiological analysis.

\section{Identification of listeria species}

Half Fraser broth (AES LAB., Combourg, France) was used as a primary selective enrichment medium. Ferric ammonium citrate (Sigma, Steinheim, Germany) was added as a supplement. Then, $25 \mathrm{gm}$ food sample was mixed with $225 \mathrm{ml}$ half Fraser broth in a stomacher bag and homogenised using a laboratory blender, stomacher$400^{\text {max }}$ (Seward Medical, London, UK) at a higher speed for two minutes and incubated at $30^{\circ} \mathrm{C}$ for $24 \mathrm{~h}$. Similarly, $25 \mathrm{ml}$ milk was sampled and $\mathrm{pH}$ adjusted to neutral and thoroughly mixed with 1:10 ratio to half Fraser broth and incubated at $30^{\circ} \mathrm{C}$ for $24 \mathrm{~h}$. On the second day, about $0.1 \mathrm{ml}$ of culture was transferred to a tube containing $10 \mathrm{ml}$ of Fraser broth (containing acriflavin hydrochloride $0.025 \mathrm{~g} / \mathrm{l}$ of distilled water and nalidixic acid $0.02 \mathrm{~g} / \mathrm{l}$ of distilled water)(AES Lab., Combourg, France) and ferric ammonium citrate. The inoculated medium was incubated at $37^{\circ}$ for $48 \mathrm{~h}$. Then a loopful of inoculum was taken from isolated colonies and streaked onto pre-dried sterile plates of PALCAM (Polymixin Acriflavin Lithium Chloride Ceftazidime Aesculin Mannitol). Plates were examined for grey-green colonies with black background, typical for Listeria spp. Selected representative colonies were further identified to species level based on haemolytic patterns and biochemical analysis, following previously described protocol by Rorvik and his associates [8].

For confirmation, from each PALCAM agar plates (BD Diagnostic Systems, Heidelberg/Germany), five colonies presumed to be Listeria species were taken and streaked onto the surface of pre-dried plates of Tryptone Soya Yeast Extract Agar (TSYEA) (Detroit, USA) and incubated at $37^{\circ} \mathrm{C}$ for $24 \mathrm{~h}$ or until growth is satisfactory. Typical colonies ( $1 \mathrm{~mm}$ to $2 \mathrm{~mm}$ in diameter, convex, colourless and opaque), were used for further biochemical tests. Gram staining, motility, haemolysis, catalase, and CAMP tests were also performed. Rhamnose (AES Lab., Combourg, France), Xylose (AES Lab., Combourg, France) and Mannitol (Merck, Darmstadt, Germany) fermentation was evaluated and positive reactions (acid formation) were indicated by a yellow colour within 24 to $48 \mathrm{~h}[9,10]$.

\section{Antimicrobial susceptibility testing}

Antimicrobial susceptibility test was performed for L. monocytogenes isolates using Kirby Bauer disc diffusion technique [11]. About 2-3 pure colonies were taken from TSYEA, suspended in Muller Hinton broth and incubated at $37^{\circ} \mathrm{C}$ for $1-2 \mathrm{~h}$. Bacterial suspension was then adjusted to 0.5 McFarland turbidity standards and transferred to Mueller-Hinton agar plate using a sterile cotton swab. Plates were seeded uniformly by rubbing the swab against the entire agar surface. After the inoculums were dried, antibiotic impregnated disks were applied to the surface of the inoculated plates using disc dispenser. The plates were then incubated aerobically at $37^{\circ} \mathrm{C}$ for $24 \mathrm{~h}$. Finally, zone of inhibition was measured 
including the disk diameter. The susceptible, intermediate and resistant categories were assigned on the basis of the critical points recommended by Clinical and Laboratory Standards Institute (CLSI) [12] and according to the manufacturer's leaflet attached to the disks. The antimicrobials (Oxoid Ltd, Basingstoke, Hampshlre, England) tested were amoxicillin (AML $20 \mu \mathrm{g}$ ), sulfamethoxazoletrimethoprime (SXT $25 \mu \mathrm{g}$ ), cephalothin (KF $30 \mu \mathrm{g}$ ), chloramphenicol (CAF $30 \mu \mathrm{g}$ ), cloxacillin (OX $30 \mu \mathrm{g}$ ), penicillin (P $10 \mu \mathrm{g})$, tetracycline (TE $30 \mu \mathrm{g})$, vancomycin (VA $30 \mu \mathrm{g})$, and gentamicin (CN $10 \mu \mathrm{g})$. Selection of antimicrobials was based on availability and frequent use of these antimicrobials in the study area both in veterinary and human medicine. L. monocytogenes ATCC 19111 were used as quality control strain.

\section{Data management and analysis}

Data was entered and analyzed using the statistical software SPSS version 20.0. Descriptive statistics was used to describe the frequency of Listeria species from different food samples, antimicrobial susceptibility pattern and hygienic conditions.

\section{Ethical clearance}

Ethical clearance was obtained from the Ethical Review Board of Institute of Public Health, University of Gondar. Written consent was received from public dinning house owners participated in this study. Confidentiality of the information was maintained throughout the study.

\section{Results}

Out of 384 food samples examined in this study, 96 (25.0\%) food samples were contaminated with Listeria species. Listeria species were isolated from raw minced beef, fish meat, pizza, raw milk, cottage cheese, cream cake and ice cream samples as tabulated in Table 1.

The highest and the lowest prevalence of Listeria were found in raw meat $(31 / 60,51.66 \%)$ and cottage cheese $(5 / 40,12.5 \%)$. All pasteurized milk $(n=50)$ samples examined were negative for Listeria species. L. monocytogenes were isolated from $24(6.25 \%)$ of the total food samples analysed and it was the second predominant Listeria species next to L. innocua (12.5\%) as indicated in Table 2. The prevalence of $L$. innocua was found to be the highest in raw meat (31.7\%) followed by raw milk (14\%) and fish meat (10\%) samples. In the current study, ice cream was the most contaminated food item (15\%) with L. monocytogenes followed by minced beef (12\%) and cream cakes (10.7\%).

\section{Antimicrobial susceptibility profile of $L$. monocytogenes} Of the total $24 L$. monocytogenes species subjected for antimicrobial susceptibility test, 16 (66.7\%) exhibited resistance for penicillin. Twelve (50\%), 9(37.5\%) and $4(16.6 \%)$ of $L$. monocytogenes were resistant to nalidixic
Table 1 Prevalence of Listeria species in food items from public dinning places in Gondar

\begin{tabular}{|c|c|c|c|c|}
\hline Sample type & $\begin{array}{l}\text { No of Sample } \\
\text { Examined }\end{array}$ & $\begin{array}{l}\text { L. monocytogenes } \\
\mathrm{N}(\%)\end{array}$ & $\begin{array}{l}\text { Other Listeria } \\
\text { specie N (\%) }\end{array}$ & $\begin{array}{l}\text { Total } \\
\text { N (\%) }\end{array}$ \\
\hline Raw meat & 60 & $4(6.66)$ & $27(45)$ & $31(51.66)$ \\
\hline Minced beef & 25 & $3(12)$ & $3(12)$ & $6(24)$ \\
\hline Fish meat & 50 & $3(6)$ & $10(20)$ & $13(26.0)$ \\
\hline Pizza & 24 & $2(8.3)$ & $5(20.8)$ & $7(29.16)$ \\
\hline $\begin{array}{l}\text { Pasteurized } \\
\text { milk }\end{array}$ & 50 & 0 & 0 & 0 \\
\hline Raw milk & 50 & $2(4.0)$ & $12(24)$ & $14(25.0)$ \\
\hline $\begin{array}{l}\text { Cottage } \\
\text { cheese }\end{array}$ & 40 & 0 & 5 & $5(12.5)$ \\
\hline Ice cream & 20 & $3(15)$ & $6(30)$ & $9(45)$ \\
\hline Cream Cakes & 65 & $7(10.7)$ & $4(6.15)$ & $11(16.9)$ \\
\hline Total & 384 & $24(6.25)$ & $72(18.75)$ & $96(25 \%)$ \\
\hline
\end{tabular}

acid, tetracycline and chloramphenicol, respectively. Of those L. monocytogenes species exhibited resistance for one or more antimicrobials, $4(16.7 \%)$ were multidrug resistance. Multidrug resistant isolates were identified from raw meat $(\mathrm{n}=2)$, minced beef $(\mathrm{n}=1)$ and fish $(\mathrm{n}=1)$. All of L. monocytogenes identified in this research were sensitive to amoxicillin, cephalothin, cloxacillin, sulfamethoxazole-trimethoprime, gentamicin and vancomycin as indicated in Table 3.

\section{Discussion}

The overall prevalence of Listeria species in all food samples examined in this study was 25\% that indicated significant public health hazard associated with consumption of contaminated foods of animal origin. The isolation rate of L. monocytogenes was comparable with other reports from Ethiopia [13,14]. This finding was also inline with the study done in Chile [15]. Relatively higher prevalence levels of L. monocytogenes were reported in foods from Norway [16] and Turkey [17]. Differences in the prevalence of $L$. monocytogenes in foods in different countries might be attributed to differences in food items composition or hygienic status of food processing plants. Furthermore the sensitivity of bacteriological detection methods could partially explain these differences.

During this study, meat and meat product foods showed relatively higher level of contamination with Listeria species. Current isolation of $L$. innocua, $L$. welshimeri and L. murrayi was in agreement with findings of other study carried out in Ethiopia [14]. The prevalence of L. monocytogenes from minced beef in the current investigation was comparable with previous report from Ethiopia [13] but higher compared with the finding of a study done in Korea [18].

As per the authors' best knowledge, L. monocytogenes, $L$. innocua and $L$. welshimeri were isolated from pizza samples 
Table 2 Distribution of Listeria species by source in Gondar town

\begin{tabular}{|c|c|c|c|c|c|c|c|c|c|c|c|}
\hline \multirow[b]{2}{*}{$\begin{array}{l}\text { Listeria species } \\
\text { isolated }\end{array}$} & \multicolumn{11}{|c|}{ Number and percentage of Listeria species isolated from the food items examined } \\
\hline & $\begin{array}{l}\text { Raw } \\
\text { meat }(\mathrm{N})\end{array}$ & $\begin{array}{l}\text { Minced } \\
\text { beef }(N)\end{array}$ & $\begin{array}{l}\text { Fish } \\
\text { (N) }\end{array}$ & Pizza(N) & $\begin{array}{l}\text { Pasteurized } \\
\text { milk (N) }\end{array}$ & $\begin{array}{l}\text { Raw } \\
\text { milk (N) }\end{array}$ & $\begin{array}{l}\text { Cottage } \\
\text { cheese(N) }\end{array}$ & $\begin{array}{l}\text { Ice } \\
\text { cream(N) }\end{array}$ & $\begin{array}{l}\text { Cream } \\
\text { cake(N) }\end{array}$ & $\begin{array}{l}\text { Total } \\
\text { (N) }\end{array}$ & $\begin{array}{l}\text { Prevalence } \\
\text { (\%) }\end{array}$ \\
\hline L.monocytogenes & 4 & 3 & 3 & 2 & 0 & 2 & 0 & 3 & 7 & 24 & 6.25 \\
\hline L. ivanovii & 2 & 0 & 0 & 0 & 0 & 0 & 0 & 0 & 0 & 2 & 0.52 \\
\hline L. innocua & 19 & 2 & 5 & 4 & 0 & 7 & 3 & 4 & 4 & 48 & 12.5 \\
\hline L. seeligeri & 2 & 0 & 2 & 0 & 0 & 1 & 0 & 0 & 0 & 5 & 1.3 \\
\hline L. welshimeri & 4 & 1 & 1 & 1 & 0 & 2 & 0 & 0 & 0 & 9 & 2.3 \\
\hline L. grayi & 0 & 0 & 0 & 0 & 0 & 2 & 0 & 0 & 0 & 2 & 0.5 \\
\hline L. murrayi & 0 & 0 & 2 & 0 & 0 & 0 & 2 & 2 & 0 & 6 & 1.6 \\
\hline Total positive & 31 & 6 & 13 & 7 & 0 & 14 & 5 & 9 & 11 & 96 & 25 \\
\hline $\begin{array}{l}\text { Sample } \\
\text { examined }\end{array}$ & 60 & 25 & 50 & 24 & 50 & 50 & 40 & 20 & 65 & 384 & \\
\hline Prevalence (\%) & 51.6 & 24 & 26 & 29.1 & 0.0 & 25 & 12.5 & 45 & 16.9 & 25 & \\
\hline
\end{tabular}

for the first time in Ethiopia in the current research. Prevalence of L. monocytogenes and other Listeria species from fish samples is in line with the research finding carried out in Japan [19] but higher than the prevalence reported from Ethiopia [20,21] and India [4,8]. The null detection rate of Listeria species from pasteurised milk comply with the previous study done in Addis Ababa, Ethiopia [13]. This might be due to the fact that pasteurisation kills Listeria and absence of contamination following pasteurisation. About $4 \%$ prevalence of L. monocytogenes from 50 raw milk samples examined was lower compared with $8.3 \%$ and $13 \%$ prevalence report from Addis Ababa, Ethiopia, respectively [14,20]. This could strengthen the fact that raw milk must be considered by the dairy processor as a source of contamination. This result might be an indication of poor hygienic and sanitary condition of the milk processing and supply chain since the origin of L. monocytogenes contamination in milk is mainly of faeces $[22,23]$.

Table 3 Antimicrobial resistance profiles of $L$. monocytogenes from food samples

\begin{tabular}{lccc}
\hline & \multicolumn{2}{c}{ Number of isolates (\%) } \\
\cline { 2 - 4 } Antimicrobial agent & Resistant & Intermediate & Susceptible \\
\hline Amoxicillin & 0 & 0 & $24(100 \%)$ \\
Cephalothin & 0 & 0 & $24(100 \%)$ \\
Chloramphenicol & $4(16.6 \%)$ & $6(25 \%)$ & $14(58.3 \%)$ \\
Cloxacillin & 0 & 0 & $24(100 \%)$ \\
Sulfamethoxazole & 0 & 0 & $24(100 \%)$ \\
Gentamicin & 0 & 0 & $24(100 \%)$ \\
Nalidixic acid & $12(50 \%)$ & $4(16.6 \%)$ & $8(33.3 \%)$ \\
Penicillin & $16(66.7 \%)$ & $3(12.5 \%)$ & $5(20.8 \%)$ \\
Tetracycline & $9(37.5 \%)$ & $2(8.3 \%)$ & $13(54.2 \%)$ \\
Vancomycin & 0 & 0 & $24(100 \%)$ \\
\hline
\end{tabular}

The increased contamination of ice cream samples with L. monocytogenes, L. innocua and L. murrayi might be due to the nature of the ice cream that provides a suitable environment with regard to $\mathrm{pH}$, water activity, nutrient availability and storage temperatures [24,25]. The prevalence of L. monocytogenes in ice cream samples in this study was comparatively higher than a report from Addis Ababa, Ethiopia [13]. This might be an indication of poor hygienic handling and preparation practices of ice cream in the current study settings. It was noted that there were no routine food safety control systems in-place in the study area. In addition, power supply interruption was common in the town which can directly affect the shelf life and hygienic quality of food items sold in the pastry shops and supermarkets [14]. Isolation of L. monocytogenes from ice cream and frozen foods indicates its survival at freezing temperature [24] which implies its increased public health significance [21]. In contrary to other studies conducted in Ethiopia and elsewhere in the world [14,21,26-29], the current study revealed no L. monocytogenes detection from cottage cheese.

Four (16.7\%) L. monocytogenes isolates identified in this study showed a multi-drug resistant profile according to the recent multidrug resistance definition [30]. Further analysis of antimicrobial susceptibility test results showed that $87.5 \%$ of the isolates were resistant at least for one or more antimicrobials tested. In addition, $66.7 \%$ of L. monocytogenes species identified were resistant to penicillin which might be ascribed to high level utilization of this antibiotic due to its relatively cheaper price and readily available nature to the local community. Penicillin is one of the most frequently prescribed drugs in the current study area for most of infectious diseases both in veterinary and human medicine that could be mentioned as one of the reasons for the development of such higher resistance profile. 
Resistance was also encountered for nalidixic acid, tetracycline and chloramphenicol which were similar with studies conducted in different countries [27,29,31]. The presence of antimicrobial resistant $L$. monocytogenes in raw food products has an important public health implication especially in developing countries where there is widespread and uncontrolled use of antibiotics [31]. The problem can be higher in Ethiopia since consumption of raw meat and milk products is very common and due to the presence of large number of high-risk population. Majority of the L. monocytogenes were susceptible to amoxicillin, cephalothin, cloxacillin, sulfamethoxazoletrimethoprime, gentamicin and vancomycin which was in agreement with the finding of an earlier study in Addis Ababa, Ethiopia [14].

\section{Conclusion}

The microbiological examination of ready-to-eat foods of animal origin samples for Listeria species in this study revealed the presence $L$. monocytogenes in varying prevalence with the exception of pasteurized milk and cottage cheese. In addition, drug resistant including multidrugresistant $L$. monocytogenes were found circulating among ready-to-eat foods of animal origin in Gondar town posing high risk of infection for consumers. Application of hazard analysis critical control point principle and treatment based on in-vitro antimicrobial susceptibility tests should be in-place. Health education about the risk of consumption of raw foodstuffs should be implemented. Further in-depth typing and drug resistant gene identification studies are recommended.

\section{Acknowledgements}

We would like to thank University of Gondar for funding and laboratory facility support for smooth accomplishment of this research. In addition, we want to acknowledge owners of the public dinning houses and their workers for their cooperation during sample collection and information gathering.

\section{Competing interests}

The authors declare that there are no competing interests.

\section{Authors' contributions}

LG involved in the conception of the research idea and methodology design, performed data analysis and interpretation, and prepared the manuscript for publication, AT carried out conception of the research idea and proposal write-up, and participated in the design of methodology and reviewed the manuscript, TB involved in laboratory work and manuscript preparation, SN, EK, ME, AF and TB participated in the data analysis and manuscript preparation. All authors read and approved the final manuscript.

\section{Author details}

'St. Paul's Hospital Millennium Medical College, Department of Microbiology, Addis Ababa, Ethiopia. ' $M a x$ Planck Institute for Heart and Lung Research, Department III-Developmental Genetics, Bad Nauheim, Germany. ${ }^{3}$ University of Gondar, Faculty of Veterinary Medicine, Gondar, Ethiopia. ${ }^{4}$ Hawassa University, School of Veterinary Medicine, Awassa, Ethiopia. ${ }^{5}$ University of Montreal, Faculty of Veterinary Medicine, Montreal, Canada.

\section{References}

1. Van de Venter T. Prospects for the future: emerging problems-chemical/ biological. In: Conference on International Food Trade Beyond 2000: Science-based Decision, Harmonization, Equivalence and Mutual Recognition Melbourne, Australia. FAO. 1999. p. 1-20.

2. Vitas Al, Garcia-Jalón VA. Occurrence of Listeria monocytogenes in fresh and processed foods in Navarra (Spain). Int J Food Microbiol. 2004;90:349-56.

3. Orsi $\mathrm{RH}$, den Bakker HC, Wiedmann M. Listeria monocytogenes lineages: Genomics, evolution, ecology, and phenotypic characteristics. Int J Medical Microbiol. 2011;301:79-96.

4. Rocourt JC, Reilly A. Epidemiology of human Listeriosis and sea foods. Int J Food Microbiol. 2000;62:197-209.

5. Teuber M. Spread of antibiotic resistance with foodborne pathogens. Cell Mol Life Sci. 1999:56:755-63.

6. CSA (Central Statistical Authority). Central Statistical Investigatory: Statistical Report. Addis Ababa, Ethiopia: Central Statistical Authority, Federal Democratic Republic of Ethiopia; 2003.

7. Michael Thrusfield. 2007. Veterinary Epidemiology. $3^{\text {rd }}$ Edition, Wiley-Blackwell publisher, Hoboken, New Jersey, USA; 151-208.

8. Rorvik LM, Caugant DA, Yndestad M. Contamination pattern of Listeria monocytogenes and other Listeria species in a salmon slaughterhouse and smoked salmon processing plant. Int J Food Microbiol. 1995;25:19-27.

9. The International Organization for Standardization (ISO). Microbiology of food and animal feeding stuffs-horizontal method for the detection and enumeration of Listeria monocytogenes. part1: Detection method ISO 11290-1. Geneva, Switzerland: Intenational Organization for Standardization; 1996.

10. Office International de Epizootics (OIE). Terrestrial manual, differentiation of Listeria species. OIE Terrestrial Manual, Paris, France; 2008, 1242.

11. Bauer AW, Kirby WMM, Sherris JC, Turck M. Antibiotic susceptibility testing by a standardized single disk method. Am J Clin Pathol. 1966;45:493-6.

12. CLSI (Clinical and Laboratory Standards Institute): Performance for antimicrobial disk susceptibility tests; approved standard, 11th edition. CLSI document M02-A11. Wayne (PA), USA. 2012, 32(1):1-76.

13. Desalegn M, Bayleyegn M, Marie-Therese T, Kleer JC, Goetz H, Wondwossen AG. Occurrence and distribution of Listeria monocytogenes and other listeria species in ready-to-eat and raw neat products. Berl Munch Tierarztl Wochenschr. 2009;122:20-4.

14. Firehiwot A. Prevalence and antimicrobial profile of Listeria monocytogenes in retail meat and dairy products in Addis Ababa and its surrounding towns, Ethiopia. MSc thesis, Addis Ababa University, Addis Ababa, Ethiopia; 2007.

15. Cordano AM, Rocourt J. Occurrence of Listeria monocytogenes in food in Chile. Int J food Microbiol. 2001;70:175-8.

16. Yang HMA, Jaykus L, Morales RA. Consumer phase risk assessment for Listeria monocytogenes in Deli meats. Risk Analysis. 2006;26(1):89.

17. Little CRD, Younas E, Louvois DJ. Microbiological quality of retail imported unprepared whole lettuce; a PHLS food working group study. J Food Prot. 1999;62(4):325-8.

18. Baek S, Lim S, Lee D, Min K, Kim C. Incidence and characterization of Listeria monocytogenes from domestic and imported foods in Korea. J food prot. 2000;63(2):186-9.

19. Ryu CHIS, Inoue S, Kumagai S. The incidence of Listeria species in retail foods in Japan. Int J Food Microbiol. 1992;16:157-60.

20. Gebretsadik S, Kassa T, Alemayehu H, Huruy K, Kebede N. Isolation and characterization of Listeria monocytogenes and other Listeria species in foods of animal origin in Addis Ababa, Ethiopia. J Infec Pub Hlth. 2011;4(1):22-9.

21. Molla B, Yilma R, Alemayehu D. Listeria monocytogenes and other Listeria species in retail meat and milk products in Addis Ababa, Ethiopia. Ethio J Health Dev. 2004;18(3):208-12.

22. Rocourt J, Bille J. Foodborne listeriosis. World Health Stat Q. 1997;50:67-73.

23. Uhitil S, Jaksic S, Petrak T, Medic H, Gumhalter-Karolyi L. Prevalence of Listeria monocytogenes and other Listeria spp. in cakes in Croatia. Food contrl. 2004;5:213-6.

24. Ferron P, Michard J. Distribution of Listeria species in confectioner's pastries from western France: Comparison of enrichment methods. Int J Food Microbiol. 1993;18:289-303.

25. Kozačinski L, Hadžiosmanovic' M, Miokovic' B, Njari B, Pranjic' D, Cvrtila Ž. The meaning of Listeria monocytogenes in veterinary sanitary inspection. Vet Archiv. 2000;70:7-13.

26. Rahimi E, Momtaz H, Sharifzadeh A, Behzadnia A, Ashtari MS, Zandi Esfahani S, et al. Prevalence and antimicrobial resistance of Listeria species isolated from 
traditional dairy products in Charar Mahal \& Bakhtiary, Iran. Bulg J VetMed. 2012;15(2):115-22.

27. Pintado CMBS, Oliveira A, Pampulha ME, Ferreira MASS. Prevalence and characterization of Listeria monocytogenes isolated from soft cheese. Food Microbiolo. 2005;22:79-85.

28. Mahmodi MM. Occurrence of Listeria monocytogenes in raw milk and dairy products in Noorabad, Iran. J Anim Vet Advances. 2010;9:16-9.3.

29. Navratilova P, Schlegelova J, Sustckova A, Napravnicova E, Lukasova J, Klimova E. Prevalence of Listeria monocytogenes in milk, meat and foodstuff of animal origin and the phenotype of antibiotic resistance of isolated strains. Vet Med Czech. 2004;49(7):243-52.

30. Magiorakos AP, Srinivasan A, Carey RB, Carmeli Y, Falagas ME, Giske CG, et al. Multidrug-resistant, extensively drug-resistant and pandrug-resistant bacteria: An international expert proposal for interim standard definitions for acquired resistance. Clin Microbiol Infect. 2012;18:268-81.

31. Sharma D, Sharma PK, Saharan BS, Malik A. Isolation, identification and antibiotic susceptibility profiling of antimicrobial resistant Listeria monocytogenes from dairy milk. Int J Microbial Res Techno. 2012;1(1):1-4.

\section{Submit your next manuscript to BioMed Central and take full advantage of:}

- Convenient online submission

- Thorough peer review

- No space constraints or color figure charges

- Immediate publication on acceptance

- Inclusion in PubMed, CAS, Scopus and Google Scholar

- Research which is freely available for redistribution 